\title{
Decomposing Organizational Productivity Changes in Acute Care Hospitals in Tennessee, 2002-2006: A Malmquist Approach*
}

\author{
Chul-Young Roh, ${ }^{* *}$ M. Jae Moon*** and Kwangho Jung*****
}

\begin{abstract}
After the passage of the Patient Protection and Affordable Care Act, the survival and the productivity of hospitals are a critical topic in health care management. This study measured the productivity of acute care hospitals in Tennessee, applying the DEA-Malmquist index, which can be decomposed into a technical efficiency and technological change index in relation to factors such as size, ownership, location, and network. This draws on utilization data and financial statements from 144 acute care hospitals in Tennessee from 2002 through 2006. The analysis indicates that community hospitals in Tennessee were generally inefficient. The community hospitals in Tennessee suffered both with respect to technological change and technical efficiency, with the latter playing a relatively more important role. This study finds the bigger-sized, urban, public or nonprofit, strategically allied hospitals to be more productive relatively speaking and suggests that community hospitals in Tennessee need to upsize their facilities or make other adjustments, such as changing their cost structure and the way they operate their facility or bringing in new management to increase productivity. Government and health policy makers also need to develop and enact health policies to ensure that hospitals are both able to make technical progress and improve efficiency and thereby increase productivity.
\end{abstract}

Keywords: DEA-Malmquist productivity index, hospital productivity, community hospitals

* This paper was supported by the National Research Foundation of Korea Grant funded by the Korean Government (NRF-2010-330-B00031 and NRF-2012-330-B00194).

** Chul-Young Roh(Corresponding Author) is an associate professor in the Department of Health Sciences at Lehman College, the City University of New York. E-mail: chulyoung. roh@lehman.cuny.edu.

*** M. Jae Moon is Underwood Distinguished Professor in the Department of Public Administration at Yonsei University.

**** Kwangho Jung is an associate professor and a researcher at the Korea Institute of Public Affairs in the Graduate School of Public Administration at Seoul National University.

Manuscript received January 12, 2013; out for review February 4, 2013; review completed March 28, 2013; accepted October 23, 2013.

The Korean Journal of Policy Studies, Vol. 28, No. 3 (2013), pp. 29-49.

(C) 2013 by the GSPA, Seoul National University 


\section{INTRODUCTION}

The health care industry in the state of Tennessee, especially the hospital market, is vital to the local economy and quality of life. In 2009, the America Hospital Association (AHA) reported that Tennessee hospitals provided about 117,500 jobs, or $9.6 \%$ of Tennessee's total employment, and generated over $\$ 29.5$ billion in revenue for the state (AHA, 2011). Owing to increasing competition among health care providers and the expansion of TennCare, however, there has been a striking reduction in health care services since 2000. ${ }^{1}$ Inpatient resources in acute care hospitals in Tennessee are being underutilized: many licensed beds are not being staffed, and those that are staffed are not being used to full capacity. ${ }^{2}$ Furthermore, acute care hospitals in Tennessee have suffered from rising health care costs. For the period from 2000to 2009, the total operating cost of acute care hospitals in Tennessee increased from about $\$ 7.6$ billion to $\$ 13.6$ billion, while the cost per patient day increased from $\$ 1,190$ to $\$ 1,955$ (Tennessee Department of Health, 2011).

In addition, the AHA expects that government reimbursements from Medicare and Medicaid to acute care hospitals in the United States to decrease by $\$ 155$ billion over the 10-year period following the passage of the Patient Protection and Affordable Care Act. While the act will extend health care coverage to at least 32 million Americans (AHA, 2010), the hospital market in Tennessee portends a hazy economic outlook. Health care stakeholders, such as hospital administrators, governing board members, creditors, federal and state governments, politicians, patients, and insurance companies should take an interest in hospital productivity because hospitals are extremely important to communities. Hospitals are the main employers in many local communities and offer an array of special programs and activities to help meet local communities' broader health and social needs in addition to providing traditional health care services and contributing to their local economies.

This study aims to measure the productivity of hospitals in Tennessee that provided general and acute care health care services from 2002 to 2006. Acute care hospitals in Tennessee run the gamut with respect to such attributes as location, size, and ownership.

1. The number of licensed beds for acute care hospitals in Tennessee dropped from 23,396 in 2000 to 22,389 in 2009 , a decrease of $4.3 \%$, while the number of staffed beds also declined, falling from 17, 605 in 2000 to 17,276 in 2009 (Tennessee Department of Health, 2011).

2. The average length of stay for acute care hospitals in Tennessee was 4.8 days in 2009, which was the shortest number of days in the 2000s (Tennessee Department of Health, 2011). 
To measure the productivity of acute care hospitals in Tennessee, this study applies the DEA-Malmquist productivity measure to an output maximization problem in order to measure the efficiency with which hospitals generate their observed levels of outputs from the resources they have available. Under the output-oriented approach, the efficiency is measured as the maximum feasible expansion of outputs as the amount of input is held constant. All other things being equal, as outputs increase, revenues will also rise.

Previous research has analyzed hospital productivity within various countries, states, and provinces (Linna, 2000; Sommersguter-Reichman, 2000; Maniadakis \& Thanassoulis, 2000; 2004; Ventura, Gonzalez, \& Carcaba, 2004; Chen 2006; Ferrari, 2006; Lyroudi, Glaveli, Koulakiotis, \& Angelidis, 2006; Roh, Park, \& Moon, 2011a; Roh, Moon, \& Park, 2011b; Roh, Moon, \& Jung, 2013). For instance, Roh and his colleagues (2013) have evaluated the annual technical efficiency disparities of Tennessee community hospitals by applying input- and output-oriented DEAs for 2002 to 2006. However, they did not measure annual differences in elasticity of productivity compared to previous years using the Malmquist productivity change index (MPI) method. They did not distinguish and compare between the technological change index and technical efficiency change index.

This study attempts to measure the productivity (elasticity) of 144 Tennessee acute community hospitals in the first years of the twenty-first by century using the DEAMalmquist index, providing estimates of both technological change and technical efficiency change for each two-year consecutive period between 2002 and 2006 and exploring the relative role of both indexes in hospital productivity.

The rest of this study is organized as follows. First, the literature on the Malmquist productivity change index in relation to hospital productivity is reviewed. Second, the research model is specified. Third, the data source and variables used are presented. Fourth, the study results on the 144 acute care hospitals in Tennessee during the period from 2002 to 2006 are presented. And finally, the implications of the results are discussed.

\section{LITERATURE REVIEW}

\section{Research on Hospital Production Function}

Production function analysis has been applied to various industries, including public utilities (Garcia \& Thomas, 2001), railways (Caves, Christensen, \& Tretheway, 1980), higher education (Cohn, Rhine, \& Santos, 1989), and hospitals (Carey, 1997). Numerous 
studies have explored appropriate functional forms and model specifications for their fields in terms of productivity and economic scale. Health production function research has struggled to identify optimal forms and models owing to a rapid increase of health care spending in most advanced countries. The health care industry in most advanced countries is one of the largest industries in the national economy, which has motivated policy analysts to try to determine an efficient production function for hospitals (Carey, 1997; Hollingsworth, 2008; Keeler \& Ying, 1996; Newhouse, 1994; Vitaliano, 1987). It is, however, difficult to define the nature of efficiency in hospital production function because of the complex delivery system of hospital services, which features intricate medical procedures and advanced technologies. Although empirical research has examined various potential sources of inefficiency in hospital production function (Hitt, 2010; Picone, Sloan, Chou, \& Taylor, 2003), hospital production function remains a black box. Various approaches to tackling the problem of hospital production function and reducing hospital costs include consideration of economies of scale and scope (Aletras, Jones, \& Sheldon, 1997; Preyra \& Pink, 2006), hospital output indexes (Gaynor, Kleiner, \& Vogt, 2012), innovative technologies (Lee, McCullough, \& Town, 2012; Skinner \& Staiger, 2009), ownership (Burgess \& Wilson, 1996; Sloan, Picone, Taylor, \& Chou, 2001), and government regulation (Dormont \& Milcent, 2005; Propper \& Reenen, 2010).

\section{Literature Review on Hospital Productivity}

The measurement of productivity changes can be assessed at various levels, such as hospital, specific health care program, and country; this study focuses on the hospital level.

Linna (2000) analyzed productivity and efficiency changes in the production function of hospitals in Finland from 1988 to 1994 using the Malmquist productivity index in order to ascertain whether health care finance reform has been effective. He used net operating costs, total number of beds, average hourly wages of labor, annual price index for local government health care expenditures, teaching status, and readmission rate for admission as input variables and the total number of emergency visits, the total sum of follow-up visits, the DRG-weighted number of total admissions, the total bed days, the number of residents, the total number of on-the-job training weeks of nurses, and the total number of impact-weighted scientific publications as output values. Linna found that after health care finance reform, productivity in Finnish hospitals improved.

Burgess and Wilson (1995) assessed productivity changes between 1985 and 1988 for a sample of U.S. hospitals of various organizational types. Their analysis focused 
on estimating technical efficiency by comparing infrastructure and outcome variables. Infrastructure variables consisted of the number of acute- and long-term-care hospital beds and the number of full-time equivalents (FTEs) represented by registered nurses, licensed practical nurses, and other clinical and nonclinical staff. Outcomes were measured by the number of acute- and long-term-care inpatient days, the number of acute care and long-term-care inpatient discharges, the number of outpatient visits, and the number of ambulatory and inpatient surgical visits. Their findings indicated that regardless of organizational type, all hospitals saw a similar decline in productivity over the period.

Sommersguter-Reichman (2000) measured the productivity change in 22 Austrian hospitals between 1994 and 1998 to try to determine what impact the reform of the hospital financing system in 1997 might have had on productivity. She used three input variables (FTE, beds, and total expenses) and two output ones (outpatients and total number of credit points) to measure the productivity. The results indicated that the Austrian hospital finance reform has led to significant improvement with respect to technological change, although there was a decline in technical efficiency caused by decline in scale efficiency, accompanied by a slight improvement in pure technical efficiency.

Ferrari (2006) explored whether competition in health care service hospitals improve the efficiency in the provision of services by collecting data on 53 acute hospitals in Scotland in the 1990s. This study measured the changes in productivity and technical efficiency of a sample of hospitals by estimating DEA frontiers and calculating Malmquist indexes of total factor productivity (TFP). Ferrari found that productivity had slightly improved on average but that technical efficiency had declined. The results indicated that there was no positive relationship between Scottish health care reform and higher efficiency and that a change in techniques was not necessarily beneficial to patients.

Chen (2006) researched the effect of Taiwan national health insurance reform on hospital efficiency and productivity from 1994 to 1998 using various models, including the Malmquist productivity index approach. Chen found that a large number of hospitals' productivity regressed due to a lack of technological progress and a decrease quality of service but that efficiency significantly improved. Also the results indicated that national health insurance reform was positively associated with hospital productivity and quality but negatively correlated with efficiency due to the increased utilization of resources and that the productivity of public hospitals significantly improved during the period.

Lyroudi et al. (2006) measured the productivity change of 10 public hospitals in Thessalonki, Greece, for 2002-2003. The output variables used in this study were 
inpatient days, income from external surgery examinations, total expenses, income from laboratory tests and other incomes, while the input variables were beds, operating costs, pharmaceutical costs, medical supply costs, other supply costs, and personal costs. They found that the productivity of hospitals improved from 1 to 1.56 .

Maniadakis and Thanassoulis $(2000,2004)$ measured the productivity of acute care hospitals in the UK over the period after the introduction of the internal market in the National Health Service, from 1991 to 1996, as well as the productivity of Greek hospitals from 1992 to 1993 . The results indicated that immediately after the health care reform the productivity of hospitals declined but began to improve thereafter so that overall there was a net progress both as far as the inputs and costs are concerned in UK. The results also suggested that the decomposition of the productivity index into technological and allocative efficiency change and cost technological change provides a clearer picture of the sources of productivity change. Maniadakis and Thanassoulis argued that the productivity increase they found was mainly a function of overall efficiency progress that was mostly attributable to allocative efficiency improvement.

Ventura et al. (2004) analyzed the productivity of 68 public hospitals in Spain during the period from 1993 to 1997, after the government introduced program contracts. The results indicate that the TFP improved about $8 \%$ over the period. Pure efficiency and scale efficiency made a contribution of $3.5 \%$ and $4.2 \%$, respectively. The decomposition of the Malmquist index in this study indicated that technological change had improved the productivity of public hospitals in Spain but that the positive effect of technological change was canceled out by negative scale effects. The authors argued that a main factor in the improvement was the managerial efficiency brought about by the program contract.

Gannon (2008) measured the productivity and efficiency in hospital production in Ireland during the period from 1995 to 1998. This study reported that productivity had declined in regional and county hospitals owned and funded by health boards, while productivity had increased in general hospitals. There was no pattern in the sources of the improvement of productivity in the general hospitals, while technological change lead to improvement in the productivity of regional and county hospitals in Ireland. Technological and efficiency changes contributed to higher levels of productivity in larger hospitals but led to lower levels of productivity in smaller hospitals.

Roh et al. (2011a) analyzed the productivity of 118 nonprofit hospitals in the United States from 1999 to 2003, applying a DEA-based Malmquist productivity change index decomposed into a technical efficiency change index and a technological change index. This study found that the productivity of nonprofit hospitals had increased, largely as a result of technological progress rather than technical efficiency improvement, and that small-sized hospitals having fewer than 130 beds were more productive 
due to technological progress. In addition, technological progress played an important role in productivity growth in innovative hospitals while efficiency improvement played a positive role in productivity growth in non-innovative hospitals.

Roh et al. (2011b) also measured the productivity of 64 Colorado community hospitals over the period from 1993 to 2003, again applying a DEA-based Malmquist productivity change index decomposed into technical efficiency change index and technological change index. They found that the productivity of community hospitals in Colorado had increased, mainly as a result of technological progress rather than technical efficiency improvement. This study suggested that to increase productivity, large community hospitals, rural hospitals, and nonprofit and public hospitals should downsize their facilities, change their cost structure and facility operation, or adopt new management practices.

\section{MODEL SPECIFICATION}

There are several methods of measuring productivity at the aggregate level or at the industrial level. Before the mid-1990s, most studies estimated the TFP using the growth accounting method, also known as the Törnquist productivity index. Despite the considerable amount of literature on the subject, there is no consensus regarding the adequate magnitude of TFP growth rates in the process of economic growth. ${ }^{3}$

One of the recent methods of estimating productivity growth is the MPI method, which became popular after the mid-1990s. This method is based on the DEA to construct a piece-wise linear production frontier for each year in a data set, although it does not use a general or specific production function form. It does not require cost and revenue shares to aggregate inputs, nor does it use a cost minimization assumption. This study adopts the MPI method to measure TFP because the data requirement with respect to output and input variables is not heavy with the MPI method. In addition, the MPI method, which is based on the concept of maximum possible production function within a set of input resources, allows us to estimate optimal hospital production function and to illustrate productivity changes for hospitals between various time periods.

3. One basic problem with the growth accounting method is its assumption of perfect competition (and thus perfect mobility, perfect divisibility of factors, constant returns to scale, and no distortion due to government regulations). It also assumes that production is always efficient—in other words, that outputs are always produced along the production possibilities frontier. 
Let the pair of observed input vector $\mathrm{xt}$ at time $\mathrm{t}$ and the corresponding observed output vector $y t$ at time $t$ be denoted as $a^{t}=\left(x^{t}, y^{t}\right)$. Then the output distance function at time $t$ is defined as

$$
\mathrm{D}^{\mathrm{t}}\left(\mathrm{a}^{\mathrm{t}}\right)=\inf _{\delta}\left\{\mid \mathrm{y}^{\mathrm{t}} / \text { is in } \mathrm{P}^{\mathrm{t}}\left(\mathrm{x}^{\mathrm{t}}\right)\right\}=\left[\sup _{\delta}\left\{\mid \mathrm{y}^{\mathrm{t}} \text { is in } \mathrm{P}^{\mathrm{t}}\left(\mathrm{x}^{\mathrm{t}}\right)\right\}\right]^{-1}
$$

where $\mathrm{P}^{\mathrm{t}}\left(\mathrm{x}^{\mathrm{t}}\right)=\left\{\mathrm{y}^{\mathrm{t}} \mid \mathrm{x}^{\mathrm{t}}\right.$ can produce $\left.\mathrm{y}^{\mathrm{t}}\right\}$ is the production set at time $\mathrm{t}$, which is convex, closed, bounded and satisfies strong disposability of $\mathrm{x}^{\mathrm{t}}$ and $\mathrm{y}^{\mathrm{t}}$ (Coelli, 1996). The scalar is a fraction, $0<1$ for all $\mathrm{y}^{\mathrm{t}} 0$, and $=1$ if $\mathrm{y}^{\mathrm{t}}$ is in the production set. Then, the MPI at time $t$ when the production set (technology) is $\mathrm{P}^{\mathrm{t}}\left(\mathrm{x}^{\mathrm{t}}\right)$ is defined as $\mathrm{M}^{\mathrm{t}}=\mathrm{D}^{\mathrm{t}}\left(\mathrm{a}^{\mathrm{t}+1}\right) /$ $\mathrm{D}^{\mathrm{t}}\left(\mathrm{a}^{\mathrm{t}}\right)$, which is the ratio of the maximum proportional changes in the observed output required to make each of the observed outputs efficient in relation to the technology at time t. Here, $\mathrm{D}^{\mathrm{t}}\left(\mathrm{a}^{\mathrm{t}}\right)$ is applied to the constant-returns-to scale benchmark. Similarly, the MPI at time $t+1$ when the production set is $\mathrm{P}^{t+1}(\mathrm{x})$ is $\mathrm{M}^{\mathrm{t}+1}=\mathrm{D}^{\mathrm{t}+1}\left(\mathrm{a}^{\mathrm{t}+1}\right) / \mathrm{D}^{\mathrm{t}+1}\left(\mathrm{a}^{\mathrm{t}}\right)$, which refers to the technology at time $t+1$. To avoid ambiguity in choosing the production set, the output-oriented MPI is then defined as the geometric mean of the MPI in two consecutive periods (Coelli, 1996; Färe, Grosskopf, Norris, \& Zang, 1994):

$$
\mathrm{MPI}^{\mathrm{t}}=\left(\mathrm{M}^{\mathrm{t}} \cdot \mathrm{M}^{\mathrm{t}+1}\right)^{1 / 2}=\left[\left(\frac{D^{t}\left(a^{t+1}\right)}{D^{t}\left(a^{t}\right)}\right)\left(\frac{D^{t+1}\left(a^{t+1}\right)}{D^{t+1}\left(a^{t}\right)}\right)\right]^{1 / 2}
$$

where MPI $>=<1$ implies productivity growth (or change) is positive, zero, or negative from time $t$ to time $t+1$. Generally, definition 2 may be decomposed into three parts,

$$
\text { MPIt }=
$$

EI

$$
=\frac{V^{t+1}\left(a^{t+1}\right)}{V^{t}\left(a^{t}\right)}\left[\left(\frac{V^{t}\left(a^{t}\right)}{D^{t}\left(a^{t}\right)}\right) /\left(\frac{V^{t+1}\left(a^{t+1}\right)}{D^{t+1}\left(a^{t+1}\right)}\right)\right]\left[\left(\frac{D^{t}\left(a^{t+1}\right)}{D^{t+1}\left(a^{t+1}\right)}\right)\left(\frac{D^{t}\left(a^{t}\right)}{D^{t+1}\left(a^{t}\right)}\right)\right]^{1 / 2}
$$

$$
\text { PI SI TI }
$$

The first term in equation 3 is called the efficiency change index (or simply efficiency index, EI, hereafter), and the second term is called the technology change index (or simply technology index, TI, hereafter). Note that the concept of the distance function can be applied to either a constant-returns-to-scale (CRS) or a variable-returns-to-scale 
(VRS) benchmark. In equation $4, \mathrm{~V}^{\mathrm{t}}\left(\mathrm{a}^{\mathrm{t}}\right)$ is the output distance function based on a variable-returns-to-scale benchmark. The ratio of $\mathrm{V}^{t+1}\left(\mathrm{a}^{\mathrm{t}+1}\right) / \mathrm{V}^{\mathrm{t}}\left(\mathrm{a}^{\mathrm{t}}\right)$ is the pure efficiency change index (or simply pure efficiency index, PI, hereafter) from time $t$ to $t+1$, based on the variable-returns-to-scale technology. The ratio, $\mathrm{V}^{\mathrm{t}}\left(\mathrm{a}^{\mathrm{t}}\right) / \mathrm{D}^{\mathrm{t}}\left(\mathrm{a}^{\mathrm{t}}\right)$, is the scale efficiency index at time $t$, which measures the output difference between the variable-returns-toscale technology and the constant-returns-to-scale technology at time t. The ratio of this difference at $t$ and $t+1$ is the scale efficiency change index from time $t$ to $t+1$, which is called the scale efficiency change index (or simply scale index, SI, hereafter).

The MPI in equation 2 is the standard definition. It is enigmatic and obscure. Figure 1 illustrates the basic concepts intuitively. To avoid the cluttering of superscripts, we denote the observed outputs for periods $t$ and $t+1$ as $y$ and $z$, respectively, and the corresponding efficient outputs at time $t$ as $y^{\prime}$ and $z^{\prime}$ along the constantreturns-to-scale technology $\mathrm{C}^{\prime}$ and those at time $\mathrm{t}+1$ as $\mathrm{y}^{\prime \prime}$ and $\mathrm{z}^{\prime \prime}$ along the constantreturns-to-scale technology $C^{\prime \prime}$, respectively. Similarly, we denote the efficient outputs at time $\mathrm{t}$ as $\mathrm{a}^{\prime}$ and $\mathrm{b}^{\prime}$ along the variable-returns-to-scale technology $\mathrm{C}^{\prime}$ and those at

Figure 1. Output Distance Function

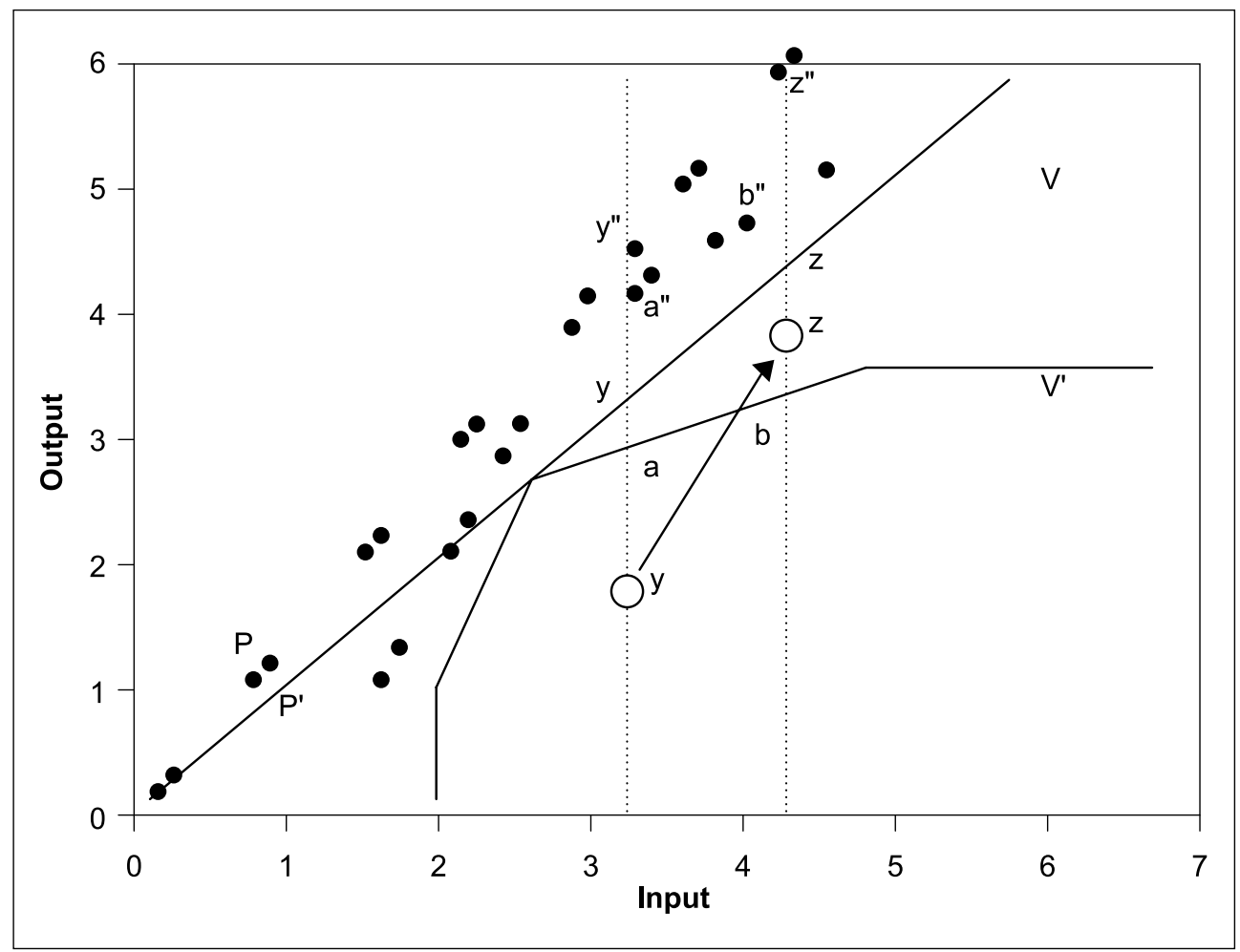


time $\mathrm{t}+1$ as $\mathrm{a}^{\prime \prime}$ and $\mathrm{b}^{\prime \prime}$ along the variable-returns-to-scale technology $\mathrm{C}^{\prime \prime}$, respectively.

Since, as figure 1 shows (see appendix), the definition of the distance function gives $\mathrm{D}^{\mathrm{t}}\left(\mathrm{a}^{\mathrm{t}}\right)=\mathrm{y} / \mathrm{y}^{\prime}$ and so forth, the definition of the MPI above reduces to equations 5 and 6 below:

$$
\begin{aligned}
\text { MPI } & =\left(\frac{z}{y}\right)\left[\left(\frac{y^{\prime}}{z^{\prime}}\right)\left(\frac{y^{\prime \prime}}{z^{\prime \prime}}\right)\right]^{1 / 2} \\
& =\left(\frac{z / z^{\prime \prime}}{y / y^{\prime}}\right)\left[\left(\frac{y^{\prime \prime}}{y^{\prime}}\right)\left(\frac{z^{\prime \prime}}{z^{\prime}}\right)\right]^{1 / 2}=\mathrm{EI} \times \mathrm{TI} \\
& =\left(\frac{z / b^{\prime \prime}}{y / a^{\prime}}\right)\left(\frac{y^{\prime} / a^{\prime}}{z^{\prime \prime} / b^{\prime \prime}}\right)\left[\left(\frac{y^{\prime \prime}}{y^{\prime}}\right)\left(\frac{z^{\prime \prime}}{z^{\prime}}\right)\right]^{1 / 2}=\mathrm{PI} \times \mathrm{SI} \times \mathrm{TI}
\end{aligned}
$$

Thus, the efficiency index EI in equation 5 is based on the constant-returns-to-scale benchmark, and the pure efficiency index PI in equation 6 is based on the variablereturns-to-scale benchmark. Both measure the ratio of the degree of deficiencies of the observed points $y$ to $\mathrm{a}^{\prime}$ in equation 6 in figure 1 (or $\mathrm{y}$ to $\mathrm{y}^{\prime}$ in equation 5) and $\mathrm{z}$ to $\mathrm{b}^{\prime \prime}$ in equation 6 (or $\mathrm{z}$ to $\mathrm{z}^{\prime \prime}$ in equation 5), relative to the corresponding maximum possible output ( $\mathrm{a}^{\prime}$ and $\mathrm{b}^{\prime \prime}$ in equation 6 and $\mathrm{y}^{\prime}$ and $\mathrm{z}^{\prime \prime}$ in equation 5), using the benchmark technology at each period. They reflect the results of learning, knowledge diffusion, spillover across the industrial sectors, improvements in market competitiveness, cost structure, capacity utilization, and so forth.

The scale index SI measures the ratios of the maximum output based on the constantreturns-to-scale technology as compared with the variable-returns-to-scale technology between the two periods. Roughly speaking, figure 1 measures the change of the line segment $a^{\prime} y^{\prime}$ in the first year to the segment $b^{\prime \prime} z^{\prime \prime}$ in the second year. It indicates the change in efficiency due to the scale of production between the two periods.

The term in the square root measures the relative movement of the productivity curves based on the constant-returns-to-scale benchmark between two periods and is the technology index TI, shown by the (geometric) average of the line segment $y^{\prime} y^{\prime \prime}$ and $z^{\prime} z^{\prime \prime}$ in figure 1 . It represents new product and process innovations, new management systems, or the external shocks that shift the production possibilities frontier.

In this paper, we refer to the output-oriented MPI simply as the productivity index. When the observed outputs are on the production possibilities curve at each period, that is, $\mathrm{y}=\mathrm{y}^{\prime}$ and $\mathrm{z}=\mathrm{z}^{\prime \prime}$, then $\mathrm{EI}=1$ and, as in Färe et al. (1994), we have TI = z/y, which is the same as the conventional definition of the TFP ratio between two periods. In addition, we comprehensively estimate the MPI in terms of hospital characteristics 
including size, location, organizational types, and strategic alliances because the degree of efficiency in hospital production function varies across those factors. Up to now little research has systematically identified the inside of the black box of hospital production function through such various hospital characteristics.

\section{DATA SOURCE AND VARIABLES USED}

The dataset used in this study was obtained from the Joint Annual Report of Hospitals and the summary reports of hospital data for the years 2002 to $2006(\mathrm{~T}=5)$ from the Tennessee Department of Health. To measure the productivity change across acute care hospitals in Tennessee, this study identified 144 community hospitals after all the variables that this study used were cleansed. The DEA-based Malmquist method provides flexibility in choosing input and output variables, and results of productivity scores proved to be consistent across various input and output variables (Lynch \& Ozcan, 1994).

In this study, three input variables were used to measures the resources used in production of acute care hospitals. The first input variable was the current assets of each hospital, which functions as a proxy for the capital input factor (resources that the hospitals either had in cash or could convert to cash within a year). Current assets point to how quickly hospitals can pay off obligations that are due in the near future and thus serve as a diagnostic indicator of the financial health and stability of hospitals (Finkler, 2005). Current assets are deflated using the consumer price index (CPI) published by the U.S. Department of Labor, Bureau of Labor Statistics. This index was scaled to 100.0 in 2002. The second input variable was the number of hospital beds in a particular hospital, which indicates the size of the hospital. Hospitals with larger number of beds should realize economies of scale more easily than hospitals with a smaller number of beds. The third input variable was the FTE for physicians and other health professionals in each hospital that stands in as a proxy of labor input factor. This variable ws intended to reflect the volume and range of work undertaken by health care professionals in the hospitals under study.

Five output variables were used in this study. The first was the number of procedures or courses of action intended to achieve a result in the care of persons with health problems that were carried out by each hospital. Procedures include medical tests used to diagnose, detect, and monitor diseases, disease processes, and susceptibility and to decide on a course of treatment along with the treatments themselves, such as surgeries. The number of procedures for each hospital indicates its productive capacity. The second output was the number of outpatient visits at each acute care hospital in 
Tennessee. This variable indicates the capacity of a hospital's outpatient care services and makes up a substantial portion of total output. The third output variable was the number of inpatient days for each acute care hospital. It provides a broad measure of the hospital's inpatient workload. Total number of inpatient days and the number of outpatient visits are widely accepted as measure of acute care hospital productivity (Harrison, Coppola, \& Wakefield, 2004). The fourth variable was the total amount of charity care (uncompensated care), or the amount of free care provided to patients who cannot pay for their health care services. Despite the fact that charity care is given away, it is not represented as a bad debt expense. The level of charity care reflects a hospital's core competency in delivering health care. Charity care was also deflated using the CPI. The last output variable was total profit, or the amount by which a hospital's annual revenues exceed its annual expenses. Total revenue reflects each hospital's core competency in health care delivery. The total profit was likewise deflated using the CPI.

Table 1 shows the year-specific descriptive statistics for the input and output variables used to measure productivity change in acute care hospitals in Tennessee from 2002 to 2006. Most input variables have increased continuously. With respect to

Table 1. Descriptive Statistics of Efficiency Variables for Individual Period, Means (Standard Deviation)

\begin{tabular}{|c|c|c|c|c|c|}
\hline & $\begin{array}{c}2002 \\
(N=144)\end{array}$ & $\begin{array}{c}2003 \\
(N=144)\end{array}$ & $\begin{array}{c}2004 \\
(N=144)\end{array}$ & $\begin{array}{c}2005 \\
(N=144)\end{array}$ & $\begin{array}{c}2006 \\
(N=144)\end{array}$ \\
\hline \multicolumn{6}{|l|}{ Input } \\
\hline Current Assets (\$) & $\begin{array}{c}13.1 \mathrm{M} \\
(14.4 \mathrm{M})\end{array}$ & $\begin{array}{c}22.9 \mathrm{M} \\
(98.2 \mathrm{M})\end{array}$ & $\begin{array}{c}23.1 \mathrm{M} \\
(106.4 \mathrm{M})\end{array}$ & $\begin{array}{l}24.5 \mathrm{M} \\
(34.9)\end{array}$ & $\begin{array}{c}24.9 \mathrm{M} \\
(35.2 \mathrm{M})\end{array}$ \\
\hline Bed & $\begin{array}{c}161.9 \\
(167.6)\end{array}$ & $\begin{array}{c}161.7 \\
(165.5)\end{array}$ & $\begin{array}{c}161.3 \\
(165.9)\end{array}$ & $\begin{array}{c}159.4 \\
(165.5)\end{array}$ & $\begin{array}{c}160.7 \\
(169.3)\end{array}$ \\
\hline FTE & $\begin{array}{c}611.5 \\
(861.8)\end{array}$ & $\begin{array}{c}621.9 \\
(868.8)\end{array}$ & $\begin{array}{c}619.1 \\
(889.0)\end{array}$ & $\begin{array}{c}620.7 \\
(911.0)\end{array}$ & $\begin{array}{c}619.7 \\
(954.5)\end{array}$ \\
\hline \multicolumn{6}{|l|}{ Output } \\
\hline Procedures & $\begin{array}{c}19404.6 \\
(28527.6)\end{array}$ & $\begin{array}{c}21267.3 \\
(30070.1)\end{array}$ & $\begin{array}{c}25480.4 \\
(40810.6)\end{array}$ & $\begin{array}{c}23978.0 \\
(34282.9)\end{array}$ & $\begin{array}{c}24883.3 \\
(35747.0)\end{array}$ \\
\hline Outpatient & $\begin{array}{c}65495.6 \\
(89496.7)\end{array}$ & $\begin{array}{c}63239.8 \\
(85300.9)\end{array}$ & $\begin{array}{c}66029.3 \\
(93138.8)\end{array}$ & $\begin{array}{c}65699.3 \\
(99687.1)\end{array}$ & $\begin{array}{c}66764.4 \\
(105665.3)\end{array}$ \\
\hline Inpatient & $\begin{array}{c}28134.4 \\
(36243.6)\end{array}$ & $\begin{array}{c}29750.8 \\
(37997.1)\end{array}$ & $\begin{array}{c}30128.1 \\
(38449.0)\end{array}$ & $\begin{array}{c}31118.7 \\
(41004.2)\end{array}$ & $\begin{array}{c}30120.4 \\
(39190.1)\end{array}$ \\
\hline Charity & $\begin{array}{c}1.9 \mathrm{M} \\
(7.0 \mathrm{M})\end{array}$ & $\begin{array}{l}2.4 \mathrm{M} \\
(9.6 \mathrm{M})\end{array}$ & $\begin{array}{c}3.1 \mathrm{M} \\
(11.7 \mathrm{M})\end{array}$ & $\begin{array}{c}3.9 \mathrm{M} \\
(16.0 \mathrm{M})\end{array}$ & $\begin{array}{c}6.4 \mathrm{M} \\
(20.3 \mathrm{M})\end{array}$ \\
\hline
\end{tabular}


the input variables, current assets are shown to have increased over the years, with a six-year average of $\$ 21.7$ million. The number of beds fluctuated over the entire period, with the average number of beds being 161. FTE increased over the years, with a five-year average of 618.6, showing that FTE is a main product among multiple input variables.

The output variables generally indicated a steadily increasing productivity: over the five-year period, the number of procedures averaged 23,002.7 (2005 being the only year the number did not go up), the number of outpatient averaged of 65,445.7, the number of inpatient days averaged 29,850.5 (2006 being the only year that did not see an increase), charity care averaged $\$ 3.5$ million, and profit averaged of 232.5 million (2002 being the only year that profits did not grow).

\section{EMPIRICAL FINDINGS}

Table 2 shows the averages of the MPI and its components (EI, TI, PI, SI) over the period. Over the period, the MPI indicates that overall productivity of acute care hospitals in Tennessee declined by $0.9 \%$ annually, and except for PI, all of MPI components likewise declined during the period. Although PI increased by $0.9 \%$, EI, TI and SI declined by $1.1 \%, 0.8 \%$ and $1.1 \%$ annually during the period. The EI reveals similar trend to the MPI during the period. The result indicates that the decrease in productivity was primarily a function of the EI. The EI is divided into two parts, PI and SI, which allows for a more detailed examination of the technical efficiency change index (Fare et al., 1994). During the period, the PI increased, while SI decreased. Technological changes, namely innovation, generally led to an increase in productivity in acute care hospitals in Tennessee during the period.

Table 2. Malmquist Productivity Change Index and Its Components

\begin{tabular}{c|c|c|c|c|c}
\hline $\begin{array}{c}\text { Period } \\
\text { MPI Component }\end{array}$ & $\begin{array}{c}2002-2003 \\
(144)\end{array}$ & $\begin{array}{c}2003-2004 \\
(144)\end{array}$ & $\begin{array}{c}2004-2005 \\
(144)\end{array}$ & $\begin{array}{c}2005-2006 \\
(144)\end{array}$ & $\begin{array}{c}2002-2006 \\
(144)\end{array}$ \\
\hline E1 & 0.873 & 0.970 & 0.921 & 1.274 & 0.989 \\
\hline T1 & 1.041 & 1.079 & 1.076 & 0.802 & 0.992 \\
\hline PI & 0.953 & 1.089 & 0.943 & 1.061 & 1.009 \\
\hline SI & 0.916 & 0.891 & 0.977 & 1.201 & 0.989 \\
\hline MPI & 0.909 & 1.046 & 0.991 & 1.022 & 0.991 \\
\hline
\end{tabular}




\section{Hospital Size}

Aspects of organizations such as size, location, ownership, and networks with other organizations indicate the effects of productivity change. Acute care hospitals can be stratified by the number of beds. Consistent with Roh et al. (2011a and 2011b), this study divides acute care hospitals in Tennessee into three groups by size: small (up to 50 beds), medium (51 to 100 beds), and large (over 100 beds). Of the 144 acute care hospitals in Tennessee under study here, 75 were classified as small, 30 as medium, and 39 as large.

Table 3 shows that the geometric mean of the MPI is 0.987 in small-sized hospitals, 1.009 in medium-sized ones, and 1.008 in large-sized ones during the period. Like Ventura et al. (2004), this result indicates that medium-sized acute care hospitals in Tennessee had the highest productivity growth, while small-sized ones showed the least productivity growth. As in Roh et al. (2011b), TI leads the productivity improvement rather than EI. EI, decomposed into PI and SI, decreases during the period. SI and EI show similar trend.

Table 3. Malmquist Productivity Change Index and Its Components by Hospital Size

\begin{tabular}{|c|c|c|c|c|c|c|}
\hline \multicolumn{2}{|c|}{$\begin{array}{c}\text { Period } \\
\text { MPI Component }\end{array}$} & $\begin{array}{c}2002-2003 \\
(144)\end{array}$ & $\begin{array}{c}2003-2004 \\
(144)\end{array}$ & $\begin{array}{l}2004-2005 \\
(144)\end{array}$ & $\begin{array}{c}2005-2006 \\
(144)\end{array}$ & $\begin{array}{c}2002-2006 \\
(144)\end{array}$ \\
\hline \multirow{3}{*}{ El } & Small $(n=75)$ & 0.890 & 0.977 & 1.050 & 1.049 & 0.989 \\
\hline & Medium $(n=30)$ & 0.993 & 0.992 & 0.959 & 1.047 & 0.997 \\
\hline & Large $(n=39)$ & 0.989 & 0.974 & 1.040 & 0.994 & 0.999 \\
\hline \multirow{3}{*}{$\mathrm{TI}$} & Small & 1.031 & 1.050 & 0.943 & 0.972 & 0.998 \\
\hline & Medium & 0.921 & 1.053 & 1.073 & 1.006 & 1.011 \\
\hline & Large & 0.923 & 1.107 & 0.958 & 1.058 & 1.009 \\
\hline \multirow{3}{*}{ PI } & Small & 0.948 & 1.089 & 0.965 & 1.030 & 1.007 \\
\hline & Medium & 1.004 & 1.000 & 0.993 & 1.009 & 1.002 \\
\hline & Large & 1.010 & 0.991 & 1.000 & 0.999 & 1.000 \\
\hline \multirow{3}{*}{ SI } & Small & 0.938 & 0.897 & 1.088 & 1.018 & 0.983 \\
\hline & Medium & 0.989 & 0.992 & 0.966 & 1.038 & 0.996 \\
\hline & Large & 0.978 & 0.983 & 1.040 & 0.995 & 0.999 \\
\hline \multirow{3}{*}{ MPI } & Small & 0.918 & 1.026 & 0.989 & 1.020 & 0.987 \\
\hline & Medium & 0.914 & 1.044 & 1.030 & 1.054 & 1.009 \\
\hline & Large & 0.912 & 1.079 & 0.996 & 1.052 & 1.008 \\
\hline
\end{tabular}




\section{Location}

This study divides Tennessee acute care hospitals into two groups by location: rural and urban. Of the 144 acute care hospitals examined, 51 acute were located in rural counties, while 93 ones were located in urban ones. Concurring with Roh et al. (2011b) and Gannon (2008), the results show that the productivity growth of acute care hospitals in urban areas is higher than that of their counterparts in rural areas during the period. The MPI of urban acute care hospitals in Tennessee progressed by $0.2 \%$, while the MPI of rural acute care hospitals regressed by $1.9 \%$.

Table 4. Malmquist Productivity Change Index and Its Components by Location

\begin{tabular}{c|l|c|c|c|c|c}
\hline \multicolumn{2}{c|}{$\begin{array}{c}\text { Period } \\
\text { MPI Component }\end{array}$} & $\begin{array}{c}2002-2003 \\
(144)\end{array}$ & $\begin{array}{c}2003-2004 \\
(144)\end{array}$ & $\begin{array}{c}2004-2005 \\
(144)\end{array}$ & $\begin{array}{c}2005-2006 \\
(144)\end{array}$ & $\begin{array}{c}2002-2006 \\
(144)\end{array}$ \\
\hline \multirow{2}{*}{ EI } & Rural $(n=51)$ & 0.871 & 1.166 & 0.993 & 0.994 & 1.001 \\
\cline { 2 - 7 } & Urban $(n=93)$ & 0.953 & 0.958 & 0.852 & 1.316 & 1.316 \\
\hline \multirow{2}{*}{ TI } & Rural & 1.022 & 0.863 & 1.030 & 1.018 & 0.981 \\
\cline { 2 - 7 } & Urban & 0.987 & 1.108 & 1.157 & 0.777 & 0.996 \\
\hline \multirow{2}{*}{ PI } & Rural & 0.911 & 1.114 & 0.963 & 1.037 & 1.003 \\
\cline { 2 - 7 } & Urban & 1.039 & 0.990 & 0.999 & 1.003 & 1.008 \\
\hline \multirow{2}{*}{ SI } & Rural & 0.956 & 1.046 & 1.032 & 0.958 & 0.997 \\
\cline { 2 - 7 } & Urban & 0.918 & 0.967 & 0.853 & 1.313 & 0.998 \\
\hline \multirow{2}{*}{ MPI } & Rural & 0.890 & 1.006 & 1.023 & 1.011 & 0.981 \\
\cline { 2 - 7 } & Urban & 0.941 & 1.061 & 0.986 & 1.023 & 1.002 \\
\hline
\end{tabular}

\section{Organization Types}

This study stratifies acute care hospitals by sector: public, not-for-profit, and forprofit hospitals. Of the144 acute care hospitals, 31 were classified as public, 64 as notfor-profit, and 49 as private. The results mirrored those found by Gannon (2008), revealing that the productivity growth of nonprofit acute care hospitals was higher than that of any other type of acute care hospitals during the period. On average, the MPI of the nonprofit hospitals progressed by $1.2 \%$ during the period, while the MPI of the public hospitals progressed by $0.5 \%$ and the MPI of the privately owned hospitals regressed by $0.9 \%$. TI is the primary source of positive productivity growth in nonprofit acute care hospitals. 
Table 5. Malmquist Productivity Change Index and Its Components by Hospital Organization Types

\begin{tabular}{c|l|c|c|c|c|c}
\hline \multicolumn{2}{c|}{\begin{tabular}{l} 
Period \\
\multicolumn{1}{c}{ MPI Component }
\end{tabular}} & $\begin{array}{c}2002-2003 \\
(144)\end{array}$ & $\begin{array}{c}2003-2004 \\
(144)\end{array}$ & $\begin{array}{c}2004-2005 \\
(144)\end{array}$ & $\begin{array}{c}2005-2006 \\
(144)\end{array}$ & $\begin{array}{c}2002-2006 \\
(144)\end{array}$ \\
\hline \multirow{4}{*}{ EI } & Public (31) & 0.990 & 0.926 & 1.126 & 0.993 & 1.007 \\
\cline { 2 - 7 } & Nonprofit (64) & 1.026 & 0.911 & 0.872 & 1.230 & 1.001 \\
\cline { 2 - 7 } & Private (49) & 0.885 & 1.089 & 1.054 & 0.976 & 0.998 \\
\hline \multirow{4}{*}{ TI } & Public & 0.903 & 1.206 & 0.902 & 1.014 & 0.999 \\
\cline { 2 - 7 } & Nonprofit & 0.888 & 1.163 & 1.203 & 0.844 & 1.012 \\
\cline { 2 - 7 } & Private & 1.003 & 0.947 & 0.918 & 1.115 & 0.993 \\
\hline \multirow{4}{*}{ PI } & Public & 1.016 & 1.002 & 0.985 & 1.020 & 1.006 \\
\cline { 2 - 7 } & Nonprofit & 1.000 & 1.045 & 0.991 & 1.001 & 1.009 \\
\cline { 2 - 7 } & Private & 1.009 & 1.009 & 1.004 & 0.993 & 1.001 \\
\hline \multirow{3}{*}{ SI } & Public & 0.975 & 0.924 & 1.145 & 0.974 & 1.001 \\
\cline { 2 - 7 } & Nonprofit & 1.025 & 0.872 & 0.880 & 1.228 & 0.991 \\
\cline { 2 - 7 } & Private & 0.877 & 0.877 & 1.049 & 0.983 & 0.996 \\
\hline \multirow{3}{*}{ MPI } & Public & 0.894 & 1.115 & 1.017 & 1.007 & 1.005 \\
\cline { 2 - 7 } & Nonprofit & 0.910 & 1.059 & 1.049 & 1.038 & 1.012 \\
\cline { 2 - 7 } & Private & 0.887 & 0.887 & 0.968 & 1.089 & 0.991 \\
\hline \multirow{2}{*}{} & & & & & & \\
\hline
\end{tabular}

\section{Strategic Alliances}

Since the 1990s, hospitals in the United States have formed alliances with health care providers as a means of coping with increasing competition and providing better health care service to their communities. Hospitals join with other hospitals, physicians, other health care providers, or community to work together to cooperate and deliver a broad spectrum of health care services to their local market, and so strategic alliances can eliminate duplication in health care services, capture economies of scale and scope, and coordinate patient care more efficiently (Clement et al., 1997). However, there have been almost no empirical studies measuring the productivity of strategic alliances in acute care hospitals using Malmquist-DEA. Of the 144 acute care hospitals in this study, 38 formed alliances with 2 or more health care providers. The result indicates that on average the MPI of acute care hospitals that formed strategic alliances with other health care providers progressed by $2.5 \%$ during the period, while the MPI of acute care hospitals that did not form such alliances regressed by $0.9 \%$ 
Table 6. Malmquist Productivity Change Index and Its Components by Presence or Absence of Strategic Alliances

\begin{tabular}{c|l|c|c|c|c|c}
\hline \multicolumn{2}{c|}{$\begin{array}{c}\text { Period } \\
\text { MPI Component }\end{array}$} & $\begin{array}{c}2002-2003 \\
(144)\end{array}$ & $\begin{array}{c}2003-2004 \\
(144)\end{array}$ & $\begin{array}{c}2004-2005 \\
(144)\end{array}$ & $\begin{array}{c}2005-2006 \\
(144)\end{array}$ & $\begin{array}{c}2002-2006 \\
(144)\end{array}$ \\
\hline \multirow{2}{*}{ EI } & Allied (38) & 1.029 & 0.975 & 0.920 & 1.054 & 0.993 \\
\cline { 2 - 7 } & Nonallied (106) & 0.844 & 0.973 & 1.163 & 1.040 & 0.998 \\
\hline \multirow{2}{*}{ TI } & Allied & 0.885 & 1.093 & 1.193 & 0.982 & 1.032 \\
\cline { 2 - 7 } & Nonallied & 1.095 & 1.074 & 0.828 & 0.998 & 0.993 \\
\hline \multirow{2}{*}{ PI } & Allied & 0.989 & 1.033 & 0.959 & 1.037 & 1.004 \\
\cline { 2 - 7 } & Nonallied & 1.034 & 0.995 & 1.002 & 0.999 & 1.008 \\
\hline \multirow{2}{*}{ SI } & Allied & 1.040 & 0.944 & 0.960 & 1.017 & 0.989 \\
\cline { 2 - 7 } & Nonallied & 0.816 & 0.977 & 1.159 & 1.041 & 0.991 \\
\hline \multirow{2}{*}{ MPI } & Allied & 0.910 & 1.066 & 1.098 & 1.036 & 1.025 \\
\cline { 2 - 7 } & Nonallied & 0.924 & 1.044 & 0.962 & 1.038 & 0.991 \\
\hline
\end{tabular}

during the same period. Also, TI was the primary source of positive productivity growth in acute care hospitals that formed strategic alliances.

\section{CONCLUSION AND POLICY IMPLICATIONS}

Our findings suggest that the overall inefficiency our study uncovered stemmed from small-sized hospitals' lack of technological progress. However, over time, improvements in pure efficiency resulted in a general improvement in overall efficiency during the period. Organizational and market attributes such as location, ownership type, size of hospital, and strategic alliances or lack thereof may have policy implications for hospital management and health care financing. Our empirical results show that productivity improved due to technological progress in medium- and large-sized hospitals. In order to improve the productivity, Tennessee community hospitals need seek economies of scale in their facilities. Generally, urban hospitals are more productive than their rural counterparts (Roh et al., 2011b), due to demographic differences, a larger market, a more competitive environment, a lower proportion of non-patient revenue, and a greater case mix (Toodi, Featherstone, \& Young 1998, p. 7). Nonprofit hospitals in Tennessee were more productive than public and private ones during the period under study. The results indicate that in the face of increasing competition among hospitals in Tennessee, hospitals that have formed strategic alliances with other 
health care providers are more productive than ones that have not.

Hospitals expect the reduction of outlays for Medicare hospitalization expenses that will follow from the passage of the Patient Protection and Affordable Care Act of 2010 to have a negative affect on their bottom line. As a key stakeholder in health care sector in the United States, governments and health policy makers should develop and enact health care policies to ensure to improve the productivity of hospitals, especially technical efficiency. The act is expected to push U.S. hospitals to increase the quality and affordability of health insurance and to operate more efficiently. Our findings suggest that consideration of hospital characteristics such as size, location, ownership, and strategic alliances or lack thereof should figure significantly in the enactment of the legislation. Specifically, governments and health policy makers should work to induce hospitals to make full use of their facilities and to form strategic alliances with other health care providers. This study also suggests that rural community hospitals should adopt the human resource management and financial management strategies used by urban community hospitals.

In this study we have looked inside the black box of hospital production function in relation to factors such as size, ownership, location, and network. Our findings emphasize the importance of a larger size and an effective network to improving the technical efficiency in Tennessee community hospitals. This study is the first one to measure the productivity of Tennessee community hospitals using the DEA-Malmquist approach. The elements of productivity —namely technical progress and technical efficiency (of which pure efficiency and scale efficiency are components)—were estimated for each two consecutive years over a five-year period.

Although our empirical analyses look at the production function of Tennessee community hospitals in relation to various factors, the production function still looks like a black box. For instance, our data does not reveal why smaller-sized hospitals have lower productivity. Future research is required to explore whether small hospitals can improve their efficiency by forming strategic alliances and embracing high technology or not, and if it is possible, how they might do so and on what timetable. While the study shows interesting findings, they are not generalizable to other sectors and other time periods. Longitudinal and panel studies are useful for examining new trends in measuring the productivity of hospitals over periods of time and should provide insightful information regarding the effect of the political and economic aspects of health care environments on productivity. Future research regarding productivity of health care organizations should include measures of health care quality. 


\section{REFERENCES}

American Hospital Association [AHA]. 2010. Legislative advisory: Summary of 2010 Health Care Reform Legislation. Chicago: AHA.

American Hospital Association [AHA]. 2011. Economic contribution of hospitals often overlooked. Chicago: AHA.

Aletras, V. H., Jones, A., \& Sheldon, T. A. 1997. Economics of scale and scope. In B. Ferguson, T. A. Sheldon, and J. Posnett (eds.), Concentration and choice in health care (pp. 23-36). London: RSM Publishing.

Burgess, J., \& Wilson, P. 1995. Decomposing hospital productivity changes, 19851988: Nonparametric Malmquist approach. Journal of Productivity Analysis, 6(4): 343-363.

Burgess, J., \& Wilson, P. 1996. Hospital ownership and technical efficiency. Management Science, 42(1): 110-123.

Carey, K. 1997. A panel data design for estimation of hospital cost functions. Review of Economics and Statistics, 79(3): 443-453.

Caves, D. W., Christensen, L. R., \& Tretheway, M. W. 1980. Flexible cost functions for multiproduct firms. Review of Economics and Statistics, 62(3): 477-481.

Caves, D. W., Christensen, L. R., \& Tretheway, M. W. 1984. Economies of density versus economies of scale: Why trunk and local service airline costs differ. RAND Journal of Economics, 15(4): 471-489.

Chen, S. N. 2006. Productivity changes in Taiwanese hospitals and the national health insurance. Service Industries Journal, 26(4): 459-477.

Clement, J., McCue, M., Luke, R., Bramble, J., Rossiter, L., Ozcan, Y., \& Pai, C. (1997). Strategic hospital alliance: Impact on financial performance. Health Affairs, 16(6): 193-203.

Coelli, T. (1996). A guide to DEAP Version 2.1: A data envelopment analysis (computer) program. CEPA Working Paper 96/08. Armidale, NSW, Australia: University of New England.

Cohn, E., Rhine, S. L.W., \& Santos, M. C. 1989. Institutions of higher education as multi-product firms: Economies of scale and scope. Review of Economics and Statistics, 71(2 ): 284-290.

Dormont, B., \& Milcent, C. 2005. How to regulate heterogenous hospitals? Journal of Economics and Management Strategy, 4(3): 591-621.

Färe, R., Grosskopf, S., Norris, S., and Zang, Z. 1994. Production growth, technical progress, and efficiency change in industrialized countries. American Economic Review, 84(1): 66-83.

Ferrari, A. 2006. Market oriented reforms of health services: A non-parametric analysis. 
Service Industries Journal, 26(1): 1-13.

Finkler, S. 2005. Financial management for public, health, and not-for-profit organizations (2nd ed.). Upper Saddle River, NJ: Pearson Education.

Gannon, B. 2008. Total factor productivity growth of hospitals in Ireland: A nonparametric approach. Applied Economic Letters, 15(2): 131-135.

Garcia, S., \& Thomas, A. 2001. The structure of municipal water supply costs: Application to a panel of French local communities. Journal of Productivity Analysis, 16: 5-29.

Gaynor, M. S., Kleiner, S. A., \& Vogt, W. B. (2012). Analysis of hospital production: An output index approach. www.andrew.cmu.edu/user/mgaynor/Assets/Draft_ 03302012.pdf.

Harrison, J. P., Coppola, M. N., \& Wakefield, M. 2004. Efficiency of federal hospitals in the United States. Journal of Medical Systems, 28(5): 411-422.

Hitt, L. 2010. The effect of IT capital on hospital efficiency. Working paper. Wharton School, University of Pennsylvania.

Hollingsworth, B. 2008. The measurement of efficiency and productivity of health care delivery. Health Economics, 17(10): 1107-1128.

Keeler, T. E., \& Ying, J. S. 1996. Hospital costs and excess bed capacity. Review of Economics and Statistics, 78(3): 470-481.

Lee, J., McCullough, J. S., \& Town, R. J. 2012. The impact of health information technology on hospital productivity. NBER Working Paper No. 18025.

Linna, M. 2000. Health care financing reform and the productivity change in Finnish hospitals. Journal of Health Care Finance, 26(3): 83-100.

Lynch, J., \& Ozcan, Y. 1994. Hospital closure: An efficiency analysis. Hospital Health Services Administration, 39(2): 205-220.

Lyroudi, K., Glaveli, N., Koulakiotis, A., \& Angelidis, N. 2006. The productive performance of public hospital clinics in Greece: A case study. Health Services Management Research, 19(2): 67-72.

Maniadakis, N., and Thanassoulis, E. 2000. Assessing productivity changes in UK hospitals reflecting technology and input prices. Applied Economics, 32(12): 1575-1589.

Maniadakis, N., and Thanassoulis, E. 2004. A cost Malmquist productivity index. European Journal of Operational Research, 154(2): 396-409.

Newhouse, J. P. 1994. Frontier estimation: How useful a tool for health economics? Journal of Health Economics, 13(3): 317-322.

Picone, G. A., Sloan, F. A., Chou, S.-Y., \& Taylor, D. H. 2003. Does higher hospital cost imply higher quality of care? Review of Economics and Statistics, 85(1): 51-62. 
Preyra, C., \& Pink, G. 2006. Scale and scope efficiencies through hospital consolidations. Journal of Health Economics, 25(5): 1049-1068.

Propper, C., \& Reenen, J. V. 2010. Can pay regulation kill? Panel Data evidence on the effect of labor markets on hospital performance. Journal of Political Economy, 118(2): 222-273.

Roh, C.-Y., Park, C.-S., \& Moon, M. J. 2011a. Economic performances of U.S. nonprofit hospitals using the Malmquist productivity change index. Journal of Management and Marketing, 8: 1-16.

Roh, C., Moon, M. J., \& Park, C. 2011b. Measuring economic performance of Colorado community hospitals using the Malmquist productivity change index. International Review of Public Administration, 16(1): 69-111.

Roh, C., Moon, M. J., \& Jung, K. 2013. Efficiency disparities among community hospitals in Tennessee: Do size, location, ownership, and network matter? Journal of Health Care for the Poor and Underserved, 24(4): 1816-1833.

Skinner, J., \& Staiger, D. 2009. Technology Diffusion and Productivity Growth in Health Care. NBER Working Paper No. 14865.

Sloan, F. A., Picone, G. A., Taylor, D. H., Jr., \& Chou, S.-Y. 2001. Hospital ownership and cost and quality of care: Is there a dime's worth of difference. Journal of Health Economics, 20(1): 1-21.

Sommersguter-Reichmann, M. 2000. The impact of the Austrian hospital financing reform on hospital productivity: Empirical evidence on efficiency and technology changes using a non-parametric input-based Malmquist approach. Health Care Management Sciences, 3(4): 309-321.

Tennessee Department of Health. 2011. Joint annual report of hospitals. Nashville: Tennessee Department of Health.

Toodi, B., Featherstone, A., \& Young, R. 1998. Efficiency analysis of hospitals in the Great Plains: An urban-rural comparison. Paper presented at the America Agricultural Economics Association Annual Meeting, August 2-5, Salt Lake City, UT.

Ventura, J., Gonzalez, E., \& Carcaba, A. 2004. Efficiency and program-contract bargaining in Spanish public hospitals. Annals of Public and Cooperative Economics, 75(4): 549-573.

Vitaliano, D. F. 1987. On the estimation of hospital cost functions. Journal of Health Economics, 6(4): 305-318. 